\title{
Gaze-cueing of attention distorts visual space
}

\section{La señalización atencional de la mirada distorsiona el espacio visual}

\author{
Recibido: junio 1 de 2012 | Revisado: agosto 1 de 2012 | Aceptado: agosto 20 de 2012
}

\author{
YUKI YAMADA * \\ Kyushu University, Yamaguchi University \\ TAKAHIRO KAWABE ** \\ NTT Communication Science Laboratories
}

\section{Doi:10.11144/Javeriana.UPSY12-5.gcad}

Para citar este artículo: Yamada, Y., \& Kawabe, T. (2013). Gaze-cueing of attention distorts visual space. Universitas Psychologica, 12(5), 1501-1510. Doi:10.11144/Javeriana.UPSY12-5.gcad

\footnotetext{
A) Kyushu University. B) Yamaguchi University. C) Japan Society for the Promotion of Science. ResearcherID: B-2671-2008. Corresponding author: Yuki Yamada. Address: Faculty of Arts and Science, Kyushu University, 744 Motooka, Nishi-ku, Fukuoka, 819-0395, Japan. E-mail: yamadayuk@ gmail.com. TEL \& FAX: +81-92-802-5837

** NTT Communication Science Laboratories. Email: kawabe.takahiro@lab.ntt.co.jp
}

\begin{abstract}
A B S T R ACT
A briefly presented peripheral flash is often mislocalized with a bias toward an attended object. The target mislocalization has been ascribed to the integration of location signals between a target and an attended object, and this results in the mislocalization of the target toward the attended object. It was unclear whether external objects that attract observer's attention were necessary to cause the target mislocalization. This study aimed at examining whether the target mislocalization occurred when the shift of observers' attention was induced by gaze cueing, in which observer's attention is shifted in the direction of other's gaze. This cueing paradigm requires no external object to attract attention, thus it enabled us to directly examine the necessity of external objects in the target mislocalization. Stimuli consisted of a pictorial face, a target, and a probe. First, the pictorial face was presented, and its gaze was shifted so as to look at either upper-right or upper-left. The target was successively presented for $50 \mathrm{msec}$. After a temporal interval of 0 or $2000 \mathrm{msec}$ was inserted as a retention interval, the probe was presented below the target. The observers' task was to judge whether the target had appeared at the left or right side of the probe location. The target was significantly mislocalized in the direction of gaze shift only when the retention interval was $2000 \mathrm{msec}$. Moreover, reaction time for detecting a target was shorter at the gazed than non-gazed location. These results suggest that the mislocalization does not require external objects attracting attention. Neural signals of target location are possibly averaged with the attention-induced local change in neural signals, and this results in the target mislocalization toward the gazed location.

Keywords authors

Visual localization, Visual attention, Gaze cueing.

Keywords plus

Perception, Signal Detection, Cognitive Science.
\end{abstract}

\section{RESUMEN}

Un flash presentado brevemente de forma periférica a menudo es mal localizado con un sesgo hacia un objeto atendido. El foco de esta mala localización se ha atribuido a la integración de las señales de localización entre un blanco y un objeto que se está atendiendo, y esto da lugar a la mala localización del objetivo hacia el objeto que se atiende. No es claro si los objetos externos que atraen la atención del observador son necesarios para causar la mala localización del objetivo. Este estudio está dirigido a examinar si la mala localización de objetivo se produce cuando el cambio de la atención del observador es inducida por las pistas de mirada, en la que la mirada del observador se desplaza en la dirección de la mirada del otro. Este paradigma de pistas no requiere de ningún objeto externo para llamar la atención, así nos permite examinar directamente la necesidad de los objetos externos en la mala localización de objetivos. Los estímulos fueron una ilustración de la cara, un objetivo, y una prueba. En primer lugar, la ilustración de la cara se presentó y la mirada se 
desplazaba hacia la parte superior derecha o superior izquierda. El objetivo fue presentado sucesivamente por $50 \mathrm{mseg}$. Después seguía un intervalo temporal de 0 o 2000 mseg como un intervalo de retención, la prueba se presentó por debajo del objetivo. La tarea de los observadores consistió en juzgar si el objetivo apareció en el lado izquierdo o derecho de la ubicación de la prueba. El objetivo fue mal localizado significativamente en la dirección de desplazamiento de la mirada sólo cuando el intervalo de retención fue de 2,000 mseg. Por otra parte, el tiempo de reacción para la detección del objetivo fue más corto en la mirada que en la localización no mirada. Estos resultados sugieren que la mala localización no requiere objetos externos que atraigan la atención. Señales neurales de la localización de objetivo se promedian con el cambio local de atención inducida en señales neurales, lo que resulta en la mala localizacion de objetivos hacia la ubicación contemplada. Palabras clave autores

Localización visual, atención visual, claves de mirada

Palabras clave descriptores

Percepción, detección de señales, ciencia cognitiva.

\section{Introduction}

Although we suppose that we can precisely and accurately localize a visual object, it is not always the case. In many situations, the subjective location of a visual object is not identical to the physical location of the object. The location of a visual object is coarsely processed in the brain (Atkinson \& Braddick, 1989; Tsal \& Bareket, 1999, 2005), and hence the localization of the object is inherently imprecise. Moreover, the localization of a visual object is susceptible to the observer's state or external visual stimuli. For example, a visual object to be localized (i.e., a target) is mislocalized towards the end point of saccadic eye movements (Honda, 1989; Matin $\&$ Pearce, 1965). A briefly presented target is mislocalized in the direction of nearby motion signals (Whitney \& Cavanagh, 2000). Adaptation to visual motion (Nishida \& Johnston, 1999) and luminance contrast (Whitaker, McGraw, \& Levi, 1997) also biases the localization of a visual target presented afterward. Thus, due to the coarse representation of a location of a visual target, the localization of the target tends to be entangled in other visual processing, resulting in the mislocalization of the target.

The spatial distribution of the observer's attention is also a critical factor for the mislocalization of a target. Specifically, the target is mislocalized repulsively from a pre-cued location (Suzuki \& Cavanagh, 1997; Pratt \& Arnott, 2008). This type of mislocalization occurs because the neural sensitivity of position coding units is inhibited around a focus of attention, and this inhibition resultantly shifts the spatial centroids of population activities of the unit, coding a target location away from the pre-cued location (Suzuki \& Cavanagh, 1997). On the other hand, a memorized location of a target is reproduced with a bias toward a pre-cued location (Yamada, Kawabe, \& Miura, 2008b, 2012; Yamada, Miura, \& Kawabe, 2011). The researchers suggest that the spatial distribution of attention modulates location signals of the target around the pre-cued location, and this leads to the mislocalization of the target toward the pre-cued location (Yamada et al., 2008b).

It was unclear whether these sorts of mislocalization of a target required external objects to exogenously capture observer's attention. Previous studies that investigated the mislocalization of a target have employed a cueing paradigm in which external objects were presented to control the location of observers' attentional focus. Because those external objects (such as a bright rectangle) have retinal stimulations at a cued location (e.g., Yamada et al., 2011, 2012), most of the previous findings are consistent with an idea that the mislocalization of a target towards the external object is caused by memory averaging between a target and an attended external object (Kerzel, 2002). Alternatively, however, it was also possible that the mislocalization of a target occurs because a location signal of a target is directly modulated by spatial distribution of observers' attention. To address this issue, it was required an alternative cueing paradigm which does not require external objects presented at a tobe attended location.

As an alternative to a conventional cueing paradigm, we raise a gaze cueing paradigm ${ }^{1}$. Previous

1 Although we could have used arrow-cueing instead of gaze-cueing, we determined to use gaze-cue because a previous study suggested that the gaze cueing effect was stronger than the arrow cueing effect (Friesen, Ristic, \& Kingstone, 2004): We preferred to use stronger directional cues (i.e., gaze cues) to more effectively investigate whether the target mislocalization occurred toward an 
studies on social attention have shown that other person's gaze shift induces observers' involuntary attentional shift in the gazing direction (e.g., Bavelier, Schneider, \& Monacelli, 2002; Friesen \& Kingstone, 1998, 2003; Friesen, Moore, \& Kingstone, 2005; Yamada, Kawabe, \& Miura, 2008a). Because the gaze cueing paradigm does not require external objects at a to-be attended location, this paradigm probably enables us to examine the mislocalization of a target towards an attended location without presenting any external objects around the target.

This study was performed to test whether the mislocalization of a target toward an attended location occurred when other's gaze controlled the shift of observers' attention. The target would be mislocalized in the direction of other's gaze if the mislocalization of a target does not require external objects to be attended.

Second, this study was designed to examine the temporal aspect of the mislocalization induced by attention shift due to other's gaze. The localization of a target has been investigated by using a relative localization task in which the target location was subjectively compared with the location of a simultaneously presented or a delayed probe. The mislocalization of a target, away from a pre-cued location, occurred when the target and probe were simultaneously presented (Suzuki \& Cavanagh, 1997; Yamada et al., 2011). On the other hand, the mislocalization of a target toward a pre-cued location occurred when the target preceded the probe by approximately $1 \mathrm{sec}$ (Yamada et al., 2008b, 2011). In this way, for a pre-cue based mislocalization of a target, the difference in temporal timing between the target and probe results in the difference in the direction of localization bias. It has not been also examined the temporal aspect of the mislocalization induced by attention shift due to other's gaze. Hence, we examined this issue by manipulating the temporal interval between the target and the probe.

attended location without the presentation of external objects at a to-be attended location.

\section{Experiment 1}

\section{Methods}

Observers. Five observers and one of the authors (YY) participated in the experiment. All had normal or corrected-to-normal visual acuity, and all except for YY were naive as to the purpose of this experiment.

Apparatus. Stimuli were presented on a 19-inch CRT monitor (RDF193H, Mitsubishi, Japan). The resolution of the monitor was $1024 \times 768$ pixels, and the refresh rate was $100 \mathrm{~Hz}$. The presentation of stimuli and collection of data were controlled by a computer (Mac Pro, Apple). Using a photometer (3298F; Yokogawa, Japan), we linearized the luminance emitted from the monitor with gamma correction. The observers' visual field was fixed using a chin-head rest, at a viewing distance of $60 \mathrm{~cm}$. The stimuli were generated by MATLAB (Mathworks Inc.) with the Psychtoolbox extension (Brainard, 1997; Pelli, 1997).

Stimuli. The stimuli consisted of a fixation cross, a pictorial face, a target, and a probe. The luminance of the fixation cross was $91.0 \mathrm{~cd} / \mathrm{m}^{2}$, and the one of the target and the probe was $1.2 \mathrm{~cd} /$ $\mathrm{m}^{2}$. The target and probe were each a small circle subtending a visual angle of $0.4^{\circ}$. The radius of the circle making the pictorial face's contour was $2.7^{\circ}$. The eyes consisted of white circles with black small circles (pupils). The radius of the white circles was $0.7^{\circ}$, and that of the black circles as pupils was $0.3^{\circ}$. A $1.7^{\circ}$ long black horizontal line was drawn as the mouth of the pictorial face. To reduce vertical spatial uncertainty, two neutral gray stripes $(43.5 \mathrm{~cd} /$ $\mathrm{m}^{2}$ ) with a height of $4^{\circ}$ and the width of the display were presented $6.13^{\circ}$ above and below the center of the display. The target was presented in the upper stripe, and the probe was presented in the lower stripe. The vertical distance between the target and probe was determined based on a previous study (Yamada et al., 2011). The other areas were filled with uniform dark gray with the luminance of $8.3 \mathrm{~cd} / \mathrm{m}^{2}$. 
The fixation cross and the pictorial face were always presented at the center of the screen, and the fixation cross was superimposed on the pictorial face. The horizontal distances between the target and the center of the display were $8^{\circ}$ (on average). The target and the probe were positioned $6.13^{\circ}$ above and below the center of the screen, respectively. The SOA between the target and the probe was set at 0 or $2000 \mathrm{msec}$ (in the $0 \mathrm{msec}$ condition the target and probe appeared and disappeared simultaneously). In each trial, the horizontal position of the target was varied in 7 or 13 steps of $0.67^{\circ}$ (0 msec condition: $-2.00,-1.33,-0.67,0.00,+0.67$, +1.33 , and $+2.00^{\circ} ; 2000$ msec condition: $-4.00,-3.33$, $-2.67,-2.00,-1.33,-0.67,0.00,+0.67,+1.33,+2.00$, $+2.67,+3.33$, and $+4.00^{\circ}$, the minus values denote positions near the center of the screen). The horizontal position of the probe was always the same as that of the target in the $0.00^{\circ}$ condition.

Procedure. The experiment was conducted in a dark room. Figure 1 shows a schematic representation of the time course of a trial in Experiment 1. The fixation cross, pictorial face, and gray stripes were presented throughout a trial. Five hundred msec after pressing the space key to start a trial, the pupils were presented in the eyes of the pictorial face for $100 \mathrm{msec}$. In the cue condition, the pupils touched the upper right or upper left inner edge of the eyes, and these made the face's gaze shift. In the no-cue condition, the pupils were presented at the center of the eyes (i.e., direct gaze). The gazed location ${ }^{2}$ was $6.13^{\circ}$ above the center of the display (i.e., this location was consistent with the vertical center of the grey stripe) and $12^{\circ}$ horizontally apart from the center of the display. In the cue condition, the visual field where the target and the probe were presented was consistent with the gazed side. In the no-cue condition, direct gaze was presented, so the gaze was neutral in the light of the consistency with the target side.

Observers were instructed to ignore the gaze directions in the pictorial face. Five hundred msec after the presentation of small black circles, the target was presented for $50 \mathrm{msec}$. After 0 or 2000 msec of the target-probe SOA, the probe was presented for $50 \mathrm{msec}$. Observers were required to judge whether the target appeared in the left

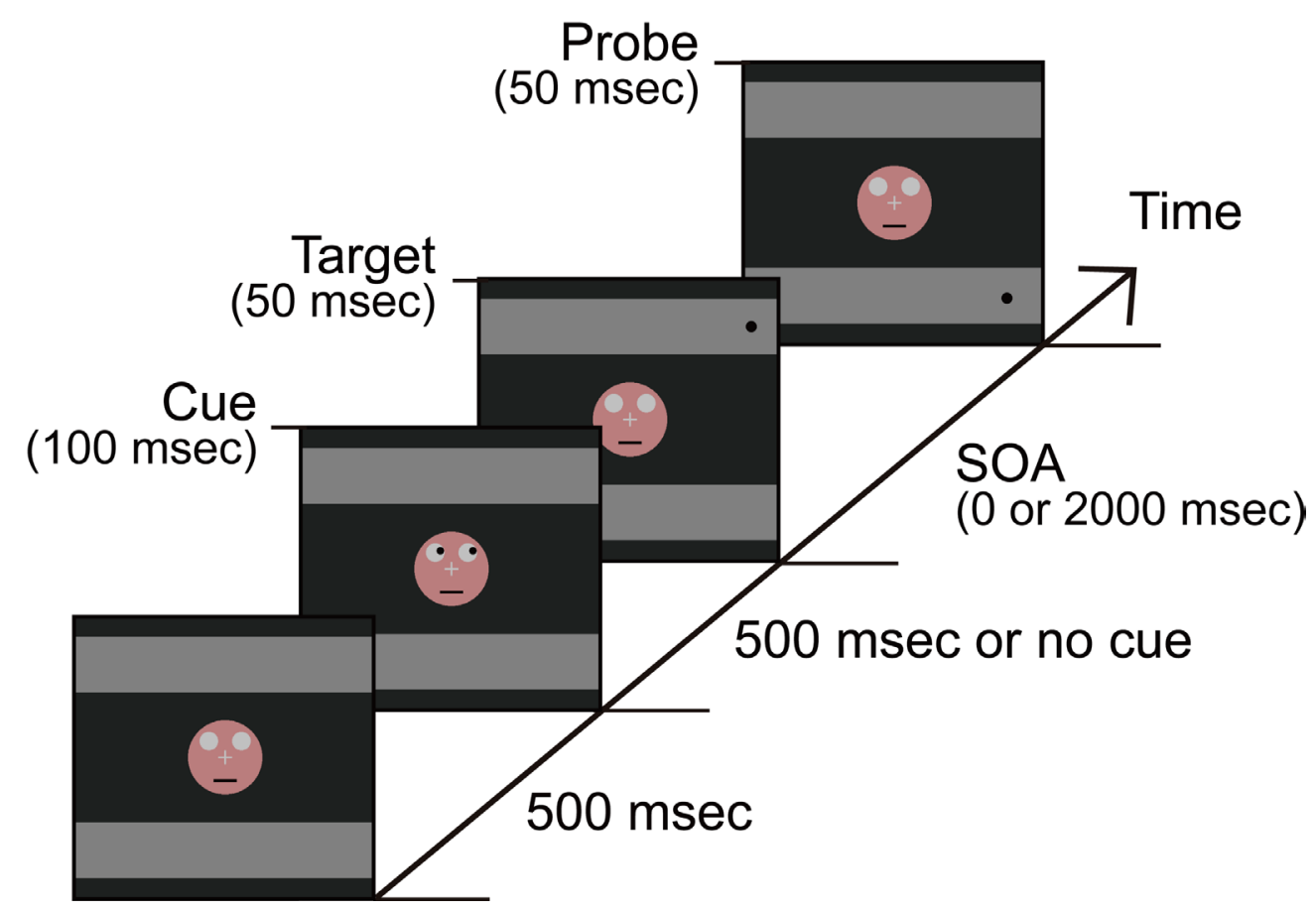

Figure 1. Stimuli and the temporal sequence of a trial in Experiment 1.

Source: Own work. 
or right of the probe. Trials were blocked with respect to each of two cue conditions (cue and no cue) and two target-probe SOA conditions ( 0 and $2000 \mathrm{msec}$ ). The reason why we blocked the cue condition was that we wanted to maximize the gaze cueing effect by having the observers anticipate that either leftward or rightward gaze shift surely occurred on each trial in the cue condition. The reason why we blocked the target-probe SOA condition was that we wanted to minimize the temporal uncertainty of the target presentation. The block order was counter-balanced across the observers. A block consisted of seven (in the 0 msec condition) or 13 (in the $2000 \mathrm{msec}$ condition) horizontal positions, two visual fields (right and left), and 10 repetitions tested in a pseudo-randomized fashion. Hence, the observers performed 800 trials in total, and it took approximately 40 minutes to complete the trials.

(a)

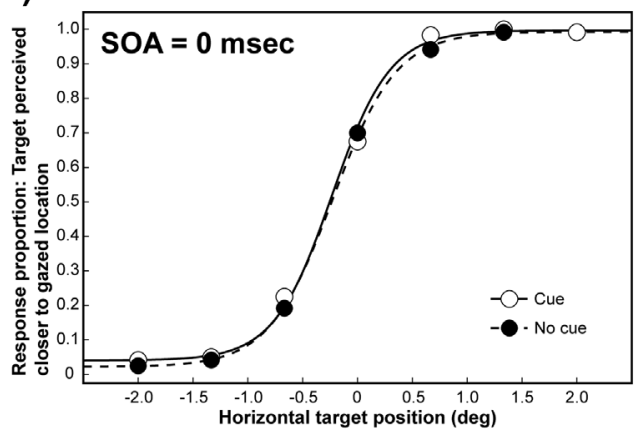

(b)

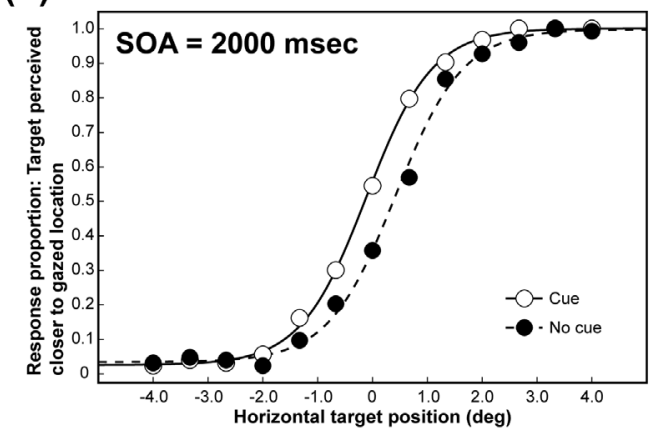

\section{Results and Discussion}

Figure 2 shows the results of Experiment 1 . By using the psignifit program implemented in MATLAB, we individually calculated the point of subjective equality (PSE) by fitting a logistic function to the proportion of the trials wherein the target was localized in the cued direction. We assessed the goodness of fit by calculating the deviance and cumulative probability estimate (Wichmann \& Hill, 2001); we confirmed that the logistic function was well fitted $(p<0.95)$. We employed the sign-inverted value of each PSE as the subjective horizontal position of the target to show that positive values denote mislocalization toward the gazed location. A two-way within-subject analysis of variance (ANOVA) on the subjective position of the target with cue (cue and no cue) and SOA (0 and $2000 \mathrm{msec}$ ) as factors revealed significant main effects of cue $(F$ $(1,5)=19.03, \operatorname{MSE}=0.024, p<0.008)$ and SOA $(F$

(c)

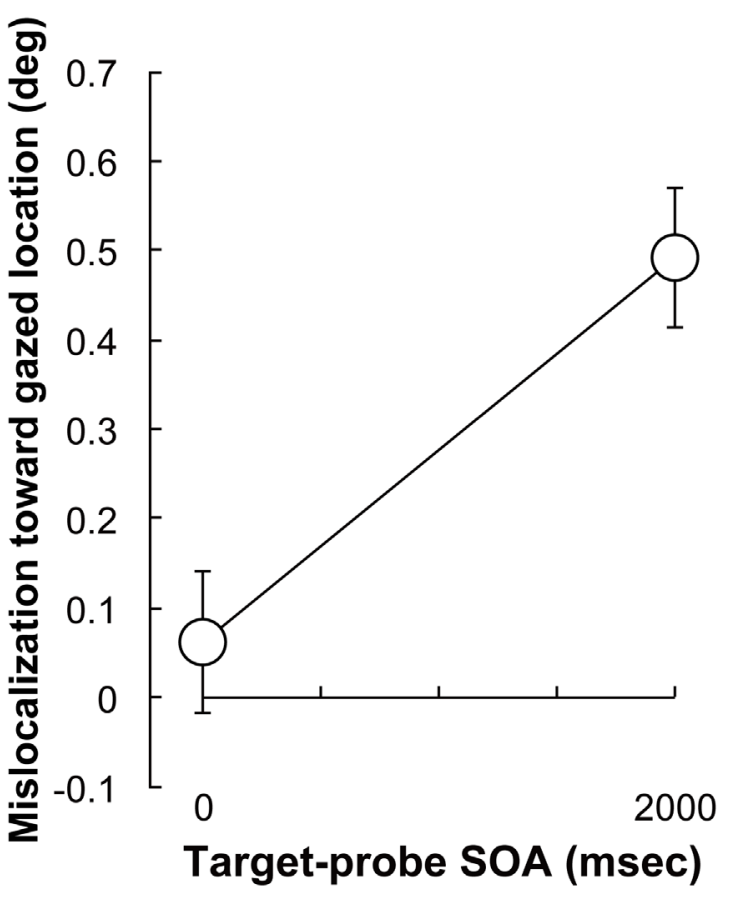

Figure 2. The results of Experiment 1. Logistic psychometric functions after pooling data from all the observers (a) in the 0 msec SOA condition and (b) in the $2000 \mathrm{msec}$ SOA condition. (c) Mean mislocalization toward gazed location. Error bars indicate within-subject standard errors of the mean (Cousineau, 2005).

Source: Own work. 
$(1,5)=9.13, \mathrm{MSE}=0.12, p<0.03)$, and a significant interaction between the factors $(F(1,5)=7.4$, MSE $=0.038, p<0.05)$.

Simple main effects based on the significant interaction revealed that in the 2000 msec condition the subjective position of the target in the cue condition significantly displaced closer to the gazed location than that in the no-cue condition $(F(1,1)$ $=23.54, \mathrm{MSE}=0.031, p<0.0008)$. On the other hand, there was no simple main effect in the $0 \mathrm{msec}$ condition $(F(1,1)=0.37, \mathrm{MSE}=0.031, p>0.55)$.

Results in Experiment 1 showed the significant mislocalization of a target toward the gazing location $^{2}$. Results suggested that the mislocalization of a target toward a pre-cued location did not require the presentation of external objects as cue stimuli. Moreover, the target was mislocalized only in the target-probe SOA of $2000 \mathrm{msec}$ condition. This is consistent with the results of Yamada et al. (2011), demonstrating that the target mislocalization toward a pre-cued location occurred after approximately $1 \mathrm{sec}$ of retention interval.

In Experiment 2, we attempted to confirm whether the gaze cue used in Experiment 1 actually directed observers' attention to the gazing location. This experiment used a pictorial face stimulus similar to the one used in Experiment 1. A target was presented at the cued location (eccentric condition) or at the location $8.00^{\circ}$ foveally offset from the cued location (foveal condition). If the gaze cue was effective in directing attention to the gazed location, the detection of a target presented would be more facilitated at the gazed (eccentric) location than at the non-gazed (foveal) location.

2 In this study, we defined the gazed location as the intersection of a horizontal straight line passing through the vertical center of the upper gray stripe and the extended straight lines each passing through both the centers of white and black circles in each eye.

\section{Experiment 2}

Methods

Observers. Eight observers (i.e., six observers participated in Experiment 1 and two additional observers) took part in Experiment 2. All had normal or corrected-to-normal visual acuity, and all except for YY were naive as to the purpose of this experiment.

Apparatus, Stimuli, and Procedure. This experiment was identical to Experiment 1 except for the followings: Four hundred msec after the presentation of the pupils, a target was presented. No probe was presented. In half of the trials (i.e., target trials), the target was presented at the location cued by gaze (eccentric condition), or at the location horizontally offset from the cued location by $8.0^{\circ}$ toward fovea (foveal condition). The observers were required to gaze at the fixation cross throughout the experiment and to press a key as quickly as possible only when the target appeared. In the other half of the trials, the target did not appear (i.e., catch trials), and the observers were required to wait for 1500 msec without response. The temporal interval from the onset of the target stimulus to the response was recorded as reaction time. Trials were blocked with respect to each of two cue conditions (cue and no cue), and the block order was counter-balanced. A block consisted of two trial types (target and catch), two target positions (eccentric and foveal), two visual fields (right and left), and 10 repetitions tested in a pseudo-randomized fashion. The observers performed 160 trials in total, and completion of the trials took about 15 minutes.

\section{Results and discussion}

A two-way within-subject ANOVA on reaction time with target location (eccentric and foveal) and cue (cue and no cue) as factors, revealed a significant main effect of target location $(F(1,7)=11.58, \mathrm{MSE}=$ $65.8, p<0.02)$ and a significant interaction between the factors $(F(1,7)=6.78$, MSE $=127.5, p<0.04)$. However, a main effect of cue was not significant $(F(1,7)=2.72, \mathrm{MSE}=639.4, p>0.14)$. Simple main 


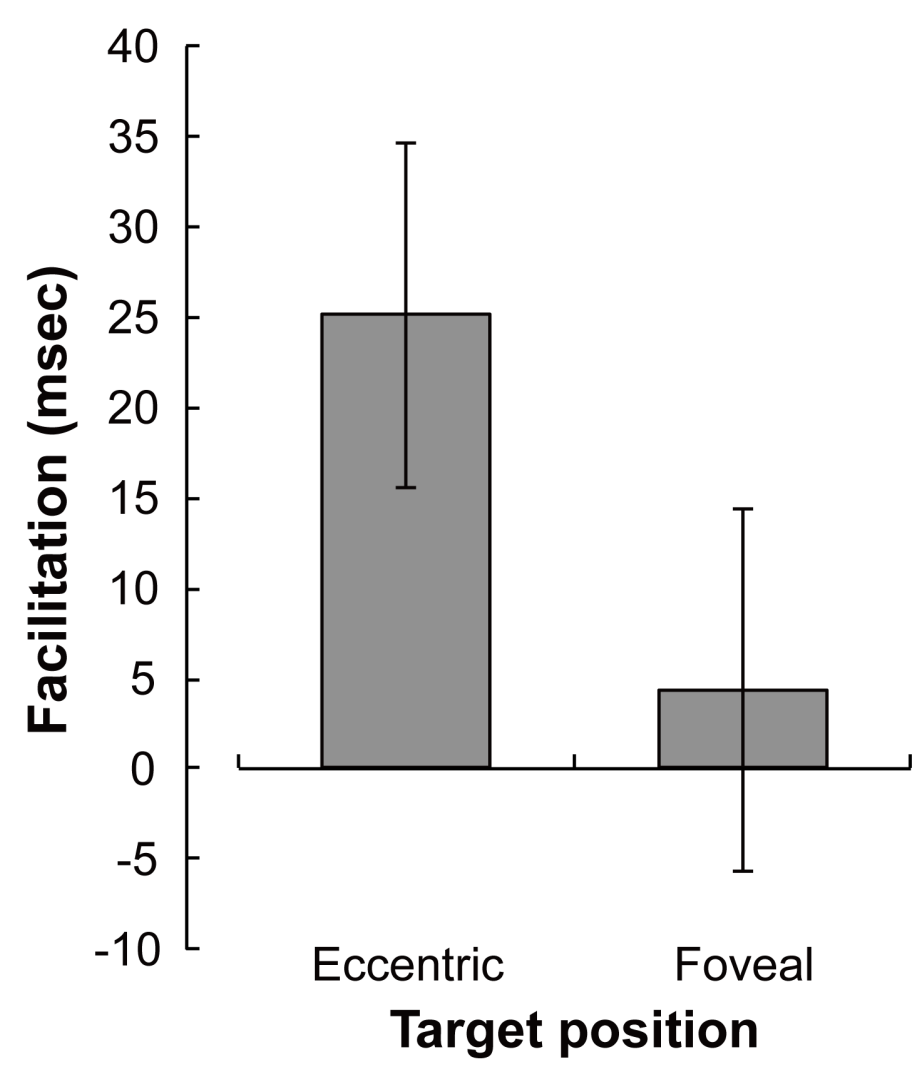

Figure 3. Results of Experiment 2. The facilitation value is calculated by subtracting reaction time with cues from reaction time without cues at each of the eccentric and foveal locations. Error bars indicate within-subject standard errors of the mean.

Source: Own work.

effects based on the significant interaction revealed that in the eccentric condition reaction time in the cue condition was significantly faster than that in the no-cue condition $(F(1,14)=6.59, \mathrm{MSE}=383.4, p$ $<0.03)$. However, in the foveal condition no difference was acknowledged between the cue and no-cue conditions $(F(1,14)=0.2, \mathrm{MSE}=383.4, p>0.66)$.

We calculated the facilitation value as the degree of processing benefit from the gaze cueing by subtracting reaction time with cues from reaction time without cues at each of the eccentric and foveal locations (Figure 3). A paired, two-tailed t-test showed that facilitation in the eccentric condition ( $25.13 \mathrm{msec} \pm 22.62 \mathrm{msec}$ for mean $\pm 95 \%$ confidence interval) was significantly larger than that in the foveal condition $(4.34 \mathrm{msec} \pm 23.68 \mathrm{msec})(t$ (7) $=2.6, p<0.04$ ).
The results showed that the detection of the target at the cued location was significantly facilitated. From the results, we confirmed that observers' attention was oriented at the gazed location in the stimulus setting as used in Experiment 1. Taken together, results in Experiments 1 and 2 suggested that the target is mislocalized towards the attended location, without external objects around the target.

\section{General discussion}

This is the first study to show that gaze-cueing of attention induced the mislocalization of a target without external objects to be attended. In Experiment 1 , the mislocalization of a target occurred towards the location where a pictorial face gazed. Furthermore, in Experiment 2 we confirmed that observers' attention was oriented to the gazed loca- 
tion. These results indicate that the mislocalization of a target toward an attended location does not require the presentation of external objects to draw observers' attention. Moreover, consistent with Yamada et al. (2011), results of Experiment 1 showed that the mislocalization of a target was found with a long retention interval (i.e., $2000 \mathrm{msec}$ ) but not with a short retention interval (i.e., $0 \mathrm{msec}$ ).

Although speculative, we have sought to explain how the mislocalization of a target toward the attended location occurs. We surmise that neural signals of the target location are directly integrated with the spatial distribution of observer's attention, and this triggers the target mislocalization toward an attended location. Visual attention causes local facilitatory effects on perceptual processing. The facilitatory effects are the most prominent at the center of attentional focus, and decrease as the distance from the focus increases, shaping the spatial distribution of attention in the visual field (Bahcall \& Kowler, 1999; Müller, Mollenhauer, Rösler, \& Kleinschmidt, 2005; Pan \& Eriksen, 1993). Thus, it is possible that attentional distribution corresponds to locally changed neural signals (e.g., Brefczynski \& DeYoe, 1999; Kastner, Pinsk, De Weerd, Desimone, \& Ungerleider, 1999). Moreover, once cued, the attention-induced local change in neural signals seems to last for a few seconds. For example, previous studies on inhibition of return (IOR) showed that IOR occurred with the cue-target SOA of $1800 \mathrm{msec}$ (Tipper, Grison, \& Kessler, 2003). This long-term IOR occurred by using a gaze cueing (Frischen \& Tipper, 2004). Facilitation effect of a gaze cueing over 3 min was also found (Frischen \& Tipper, 2006). In this way, the attention-induced local change in neural signals can be retained at least for several seconds.

We suggest that the attention-induced local change in neural signals may have interplay with neural signals induced by a target. Previous studies have shown that location information of a target and non-target stimuli is averaged with optimal weights (Greenwood, Bex, \& Dakin, 2009; Wright, Morris, \& Krekelberg, 2011). In a similar way, it is possible that the neural signals of target location are averaged with the attention-induced local change in neural signals. In the case of a long retention interval (i.e., $2000 \mathrm{msec}$ in Experiment 1), neural representation of a target may get weaker than that at the moment of the onset of the target; this signal decay also decreases the reliability of location information of the target. Therefore, if the locally changed neural signals at the gazed location may serve as a reliable source for location, the integration of the target location with the locally changed neural signals will result in the mislocalization of the target towards the attended location only in the target-probe SOA of $2000 \mathrm{msec}$.

One can argue that the direction of the gaze itself affected the judgment of the target location. That is, for example, the probability of rightward response might have increased because the gaze shifted rightward. The gaze-direction based response bias can also explain the effect of the retention interval on the mislocalization of a target in Experiment 1: The target mislocalization might occur in the 2000 msec condition because the response bias became observable as neural representation of a target got weak with the long retention interval. Further empirical studies are warranted to clarify whether and how the neural signals of target location are actually integrated with the attention-induced local change in neural signals.

\section{Conclusions}

In sum, this study investigated whether the mislocalization of a target toward an attended location occurred without external objects to be attended. Consequently, the target mislocalization occurred towards an attended location even when observers' attention was controlled by gaze cueing only with the target-probe SOA of $2000 \mathrm{msec}$. From these results, we proposed the integration between neural signals of the target location and an attention-induced local change in neural signals. 


\section{References}

Atkinson, J., \& Braddick, O. J. (1989). 'Where' and 'what' in visual search. Perception, 18, 181-189.

Bahcall, D. O., \& Kowler, E. (1999). Attentional interference at small spatial separations. Vision Research, 39, 71-86.

Bavelier, D., Schneider, K. A., \& Monacelli, A. (2002). Reflexive gaze orienting induces the line-motion illusion. Vision Research, 42, 2817-2827.

Brainard, D. H. (1997). The psychophysics toolbox. Spatial Vision, 10, 433-436.

Brefczynski, J. A., \& DeYoe, E. A. (1999). A physiological correlate of the 'spotlight' of visual attention. Nature Neuroscience, 2, 370-374.

Cousineau, D. (2005). Confidence intervals in withinsubject designs: A simpler solution to Loftus and Masson's method. Tutorials in Quantitative Methods for Psychology, 1, 75-78.

Friesen, C. K., \& Kingstone, A. (1998). The eyes have it!: Reflexive orienting is triggered by nonpredictive gaze. Psychonomic Bulletin $\mathcal{E}$ Review, 5, 490-495.

Friesen, C. K., \& Kingstone, A. (2003). Abrupt onsets and gaze direction cues trigger independent reflexive attentional effects. Cognition, 87, B1-B10.

Friesen, C. K., Moore, C., \& Kingstone, A. (2005). Does gaze direction really trigger a reflexive shift of spatial attention? Brain and Cognition, 57, 66-69.

Friesen, C. K., Ristic, J., \& Kingstone, A. (2004). Attentional effects of counterpredictive gaze and arrow cues. Journal of Experimental Psychology: Human Perception and Performance, 30, 319-329.

Frischen, A., \& Tipper, S. P. (2004). Orienting attention via observed gaze shift evokes longer-term inhibitory effects: Implications for social interactions, attention, and memory. Journal of Experimental Psychology: General, 133, 516-533.

Frischen, A., \& Tipper, S. P. (2006). Long-term gaze cueing effects: Evidence for retrieval of prior states of attention from memory. Visual Cognition, 14, 351-364.

Greenwood, J. A., Bex, P. J., \& Dakin, S. C. (2009). Positional averaging explains crowding with letter-like stimuli. Proceedings of the National Academy of Sciences of the United States of America, 106, 13130-13135.
Honda, H. (1989). Perceptual localization of visual stimuli flashed during saccades. Perception $\mathcal{E}$ Psychophysics, 45, 162-174.

Kastner, S., Pinsk, M. A., De Weerd, P., Desimone, R., \& Ungerleider, L. G. (1999). Increased activity in human visual cortex during directed attention in the absence of visual stimulation. Neuron, 22, 751-761.

Kerzel, D. (2002). Attention shifts and memory averaging. The Quarterly Journal of Experimental Psychology, 55, A, 425-443.

Matin, L., \& Pearce, D. G. (1965). Visual perception of direction for stimuli flashed during voluntary saccadic eye movements. Science, 148, 1485-1487.

Müller, N. G., Mollenhauer, M., Rösler, A., \& Kleinschmidt, A. (2005). The attentional field has a Mexican hat distribution. Vision Research, 45, 1129-1137.

Nishida, S., \& Johnston, A. (1999). Influence of motion signals on the perceived position of spatial pattern. Nature, 397, 610-612.

Pan, K., \& Eriksen, C. W. (1993). Attentional distribution in the visual field during same-different judgments as assessed by response competition. Perception and Psychophysics, 53, 134-144.

Pelli, D. G. (1997). The Video Toolbox software for visual psychophysics: Transforming numbers into movies. Spatial Vision, 10, 437-442.

Pratt, J., \& Arnott, S. R. (2008). Modulating the attentional repulsion effect. Acta Psychologica, 127, 137-145.

Suzuki, S., \& Cavanagh, P. (1997). Focused attention distorts visual space: An attentional repulsion effect. Journal of Experimental Psychology: Human Perception and Performance, 23, 443-463.

Tipper, S. P., Grison, S., \& Kessler, K. (2003). Long-term inhibition of return of attention. Psychological Science, 14, 19-25.

Tsal, Y., \& Bareket, T. (1999). Effects of attention on localization of stimuli in the visual field. Psychonomic Bulletin $\mathcal{E}$ Review, 6, 292-296.

Tsal, Y., \& Bareket, T. (2005). Localization judgments under various levels of attention. Psychonomic Bulletin EO Review, 12, 559-566.

Whitaker, D., McGraw, P. V., \& Levi, D. M. (1997). The influence of adaptation on perceived visual location. Vision Research, 37, 2207-2216. 
Whitney, D., \& Cavanagh, P. (2000). Motion distorts visual space: shifting the perceived position of remote stationary object. Nature Neuroscience, 3, 954-959.

Wichmann, F. A., \& Hill, N. J. (2001). The psychometric function. I. Fitting, sampling, and goodness of fit. Perception $\mathcal{E}$ Psychophysics, 63, 1293-1313.

Wright, J. M., Morris, A. P., \& Krekelberg, B. (2011). Weighted integration of visual position information. Journal of Vision, 11(14):11, 1-16. doi:10.1167/11.14.11.
Yamada, Y., Kawabe, T., \& Miura, K. (2008a). Dynamic gaze cueing alters the perceived direction of apparent motion. Psychologia, 51, 206-213.

Yamada, Y., Kawabe, T., \& Miura, K. (2008b). Mislocalization of a target toward subjective contours: Attentional modulation of location signals. Psychological Research, 72, 273-280.

Yamada, Y., Kawabe, T., \& Miura, K. (2012). One's own name distorts visual space. Neuroscience Letters, 531, 96-98.

Yamada, Y., Miura, K., \& Kawabe, T. (2011). Temporal course of position shift for a peripheral target. Journal of Vision, 11(6):6, 1-12. doi:10.1167/11.6.6. 